\title{
Last Generation Solar Cells in Outer Space: A STEM Outreach Project with Middle and High School Students in Colombia
}

Jose Dario Perea ${ }^{1 *}$, Diana Carolina Gasca ${ }^{2}$, Ghisliane Echeverry-Prieto ${ }^{3}$, Valentina Quiroga-Fonseca ${ }^{4}$, Carolina Orozco-Donneys ${ }^{5}$, Leidy Catherine Díaz-Montealegre ${ }^{6}$, Alejandro Ortiz ${ }^{7}$, Giovanny Molina ${ }^{3}$, Daniel Cruz ${ }^{8}$, Aaron Persad ${ }^{9}$, Sai Nithin Redd-Kantareddy 9, Josua Wachsmuth 10,

Thomas Heumueller ${ }^{11}$, Christoph Brabec ${ }^{12}$, Victor Alfonso Rodriguez-Toro ${ }^{13}$, Carolina Salguero ${ }^{14}$

${ }^{1}$ University of Toronto, Department of Chemistry, Toronto, CANADA

${ }^{2}$ Soft Coating Production Line, Tecnoglass Inc., Barranquilla, COLOMBIA

${ }^{3}$ Facultad de Ciencias Naturales y Exactas, Universidad del V alle, Cali, COLOMBIA

${ }^{4}$ Department of Physics, Universidad de los Andes, Bogotá, COLOMBIA

${ }^{5}$ Universidad Icesi, Facultad Ingeniería, Departamento Ingeniería Bioquímica, Cali, COLOMBIA

${ }^{6}$ Servicio Nacional de Aprendizaje Regional valle - SENA, COLOMBIA

${ }^{7}$ Heterocyclic Compounds Research Group_-GICH and Bioinformatics and Photonics-CIBioFi, Universidad del Valle, Cali, COLOMBIA

${ }^{8}$ Fritz. Haber Institute of the Max Planck Society, Berlin, GERMANY

${ }^{9}$ Department of Mechanical Engineering, Massachusetts Institute of Technology, Cambridge, MA 02139, USA

${ }^{10}$ Solar Factory of the Future (SFF), Bavarian Center for Applied Energy Research (ZAE Bayern), Nürnberg, GERMANY

${ }^{11}$ Institute of Materials for Electronics and Energy Technology (i-MEET), Friedrich-Alexander University, Nürnberg, GERMANY

${ }^{12}$ Helmboltz. Institute Erlangen-Nürnberg for Renewable Energy (HIERN), 91058 Erlangen, GERMANY

${ }^{13}$ School of Electrical and Computer Engineering, Georgia Institute of Technology, Atlanta, GA, USA

${ }^{14}$ From the Lab to the Field (Del Laboratorio al Campo), San Andrés, Providencia y Santa Catalina, COLOMBIA

*Corresponding Author: josedario.pereaospina@utoronto.ca

Citation: Perea, J. D., Gasca, D. C., Echeverry-Prieto, G., Quiroga-Fonseca, V., Orozco-Donneys, C., DíazMontealegre, L. C., Ortiz, A., Molina, G., Cruz, D., Persad, A., Redd-Kantareddy, S. N., Wachsmuth, J., Heumueller, T., Brabec, C., Rodriguez-Toro, V. A. and Salguero, C. (2021). Last Generation Solar Cells in Outer Space: A STEM Outreach Project with Middle and High School Students in Colombia. European Journal of STEM Education, 6(1), 12. https://doi.org/10.20897/ ejsteme/11353

Published: November 18, 2021

\begin{abstract}
As part of an unprecedented collaborative outreach effort, we implemented an innovative STEM outreach project, where more than 80 middle and high school students from different traditionally underrepresented school districts in Colombia -with no previous knowledge on material science or photovoltaics- created Last Generation Solar Cells (LGSCs) that were part of several suborbital spaceflight missions. As a result, the students were able to contrast visual and instrumental data obtained from the solar cells and modules that were launched to space with similar samples that remained on earth to measure the degradation that occurs during spaceflight conditions. At the same time, the students that participated were able to cultivate their curiosity, strengthen their scientific skills and increase their interest in pursuing careers in STEM fields.

These experiences were possible thanks to an extraordinary collaborative network between public and private entities and the use of project-based education as a powerful driver of development, especially for low-to-middle-income countries, such as Colombia. Here, we share our methodology for constructing photovoltaic devices in rural settings, and we show the progression and impact of this novel scientific outreach project.
\end{abstract}

Keywords: STEM education, science outreach, organic solar cells, last generation solar cells 


\section{INTRODUCTION}

Increased community participation and understanding of the importance of the contributions of the STEM (Science, Technology, Engineering, and Mathematics) fields are thought to be drivers of social change (KendallTaylor, 2020). Since STEM education has the potential of strengthening a country's economy, educational programs with an emphasis in science, mathematics, technology, and engineering have become a worldwide priority (Quigley, 2016; Kelley and Knowles, 2016). A good example of how STEM education can generate a technology-based society is South Korea, where the National STEM program implemented educational strategies for teaching science, technology, engineering, arts, and mathematics in all school grades (Nationales MINT (STEM) Forum, 2014; Kang, 2019).

Because providing educational services and programs aimed at the democratization and appropriation of scientific knowledge requires large investments for the implementation of nationwide STEM educational strategies, integrating such strategies in the educational systems of low-to-middle-income countries has proven to be very difficult. That is, while the challenges of implementing STEM educational strategies vary from country to country, the lack of resources, the resistance to changes in the curriculum, and social inequality are very common issues in countries with high rates of poverty and poor infrastructure (Savage, 2018). For instance, Colombia has suffered from a diverse range of socio-economic issues that arise from widely spread corruption, drug trafficking, and an ongoing civil conflict that has severely affected rural communities for more than six decades. Even though the Colombian government signed a peace agreement with one of the many armed groups that have taken part in the armed conflict, other armed groups are still waging a war that continues to affect rural communities (LeGrand et. al, 2017). Hence, in the last few decades, governmental spending has focused more on the civil conflict rather than on improving educational strategies, making it very difficult to access basic educational services for rural students in certain regions of the country.

In a recent effort to strengthen STEM competences in public schools, the Colombian government changed from an educational model, where some students attend school in the morning, while others attend school in the afternoon, to an educational model where all students spend a full day in school. In this model, all students would focus on learning specific competences during the afternoon classes. In addition, the government implemented an after-school program for students in some of the most underprivileged communities to incentivize research and strengthen STEM competences (Salazar-Lara, 2020). Yet, even with all the governmental and private efforts combined, the most recent results from the Programme for International Student Assessment (PISA) show that the proficiency in mathematics, science and a new innovative domain in Colombia are below the mean. That is, while on average $11 \%$ of the students in OECD countries scored at Level 5 or higher in mathematics, only $1 \%$ of Colombian students are in the same category and a negligible percentage of students were top performers in science (OECD, 2019). These results show that there is a need for articulating different economic and academic sectors with international cooperation to implement active learning and project-based strategies at a national level that can focus STEM education to solve real and practical problems.

In search of strategies that can strengthen STEM education in different rural areas of Colombia, we have created a network of collaborations between public and private entities that have come together to work with middle and high school students, one of the population groups with the greatest potential for social transformation. Here, we present a methodology based on a collaborative scheme between several organizations that bring together highly recognized international scientific actors to collaborate in an avant-garde scientific experience that recreates real lab experiences in rural settings: first, the students learn the theory behind photovoltaic devices, and then they create last generation solar cells that are used in experiments held in outer space.

\section{FROM HIGHSCHOOL TO SPACE: OUR METHODOLOGICAL APPROACH}

Through the advancement of new technologies, space exploration has evolved from an endeavor that was only accessible and funded by powerful governments to become a commercial and academic enterprise driven by private initiatives (Smith et al. 2012, Bugga and Brandon, 2020; Ackerman, 2020). According to the Media Lab from the Massachusetts Institute of Technology, space exploration has the potential of reaching more citizens than ever before. Hence, to prepare the new generations of professionals that will dedicate their lives to space exploration, it is necessary to enhance educational initiatives in the STEM fields around the world.

Educational initiatives related to space exploration including CubeSats, Cubes in Space and Project Possum, amongst others, provide the infrastructure required for certain underrepresented groups to participate indirectly in space exploration through experiments that are sent to outer space. However, the lack of local infrastructure and the limitations of resources that are faced by students from low-to-middle-income countries, eclipse the relevance of their scientific contributions. In our case, the following considerations were made taking into account the vast limitations of the rural settings where our outreach program take place: 


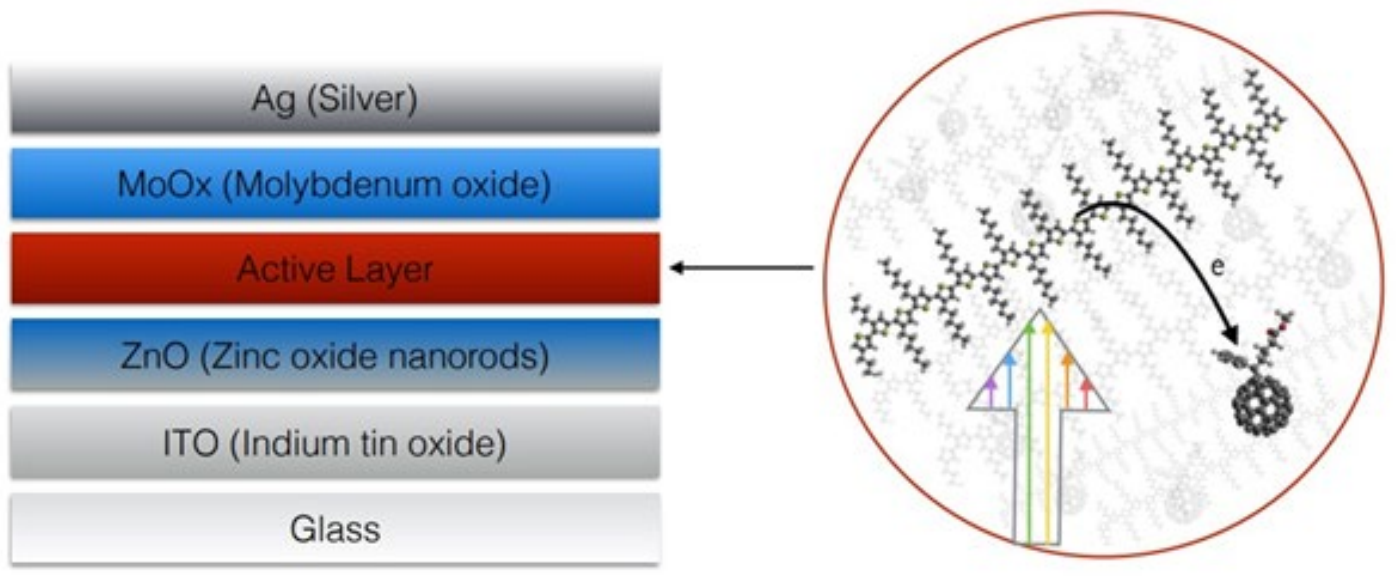

Figure 1. Illustration of the basic structure of organic solar cells showing the composition of the different layers (Perea, 2019)

- Knowing that a controlled atmosphere is difficult to guarantee in most rural lab settings, the devices are designed to minimize their immediate degradation.

- Since there is no access to solar monitoring systems in rural lab settings, a set of control Organic Solar Cells (OSCs) are built at the Friedrich Alexander University (FAU) facilities to help characterize their performance and visualize the near power conversion efficiencies.

- In-house made spin coaters are especially built to create a real lab experience in rural settings.

Since 2017, our team has been developing a unique lab experience for middle and high-school students from different public schools in which they could create a set of OSCs with the minimum technological requirements. Taking in consideration that the experiments involved in the production of solar photovoltaic devices often require expensive materials and sophisticated techniques, our team coordinated a successful -yet very simple- experimental design. For such purpose, our team received financial and scientific support from SENA, Science Clubs Colombia and the FAU in Germany, including Professor Christoph Brabec and Dr. José Darío Perea, who saw in the project a powerful way to motivate participants to achieve scientific vocations.

\section{MAKING LAB-SCALE ORGANIC SOLAR CELLS IN RURAL SETTINGS}

Before starting the experimental section, the students are introduced to the lab safety rules and the basic concepts involved in photovoltaic solar power. Once the students are able to understand basic concepts, the instructors can focus on the theories behind the experimental techniques and the specific procedures that are required to make organic solar cells.

Briefly, our students create OSCs with three parts that allow for the photo-generation and collection of charges, which consists of electrons and holes: the first part is an electron-collecting electrode or bottom electrode; the second part is composed of photoactive materials, such as polymers and small molecules that absorb the sunlight and generate free charges; and a third part that constitutes the hole-collecting electrode or top electrode (Figure 1). Hence, the direction of the photogenerated current is set by the different properties of the materials used in the top and bottom electrodes.

Each of the OSCs parts are composed of one or two thin layers of intermixed or pure materials. That is, the bottom electrode is a glass substrate coated with patterned Indium Tin Oxide that is spin-coated with a thin layer of Zinc Oxide, processable from solution, to facilitate the collection of electrons. In the second part of the OSCs, where the electric charge is generated, different organic semiconductors are used. For instance, semiconductors such as an electron donor called P3HT, and an electron acceptor that can be either a non-fullerene acceptor oIDTBR or the fullerene electron acceptor PCBM can be used. In our case, intermixed solutions of P3HT:PCBM and P3HT:o-IDTBR were spin-coated to create the photoactive thin-film. For the top electrode, which is used to collect the holes, we used a thin layer of Molybdenum Oxide and a thicker layer of either Silver or Aluminum. These two layers were deposited in sequential steps by thermal evaporation.

To build OSCs in rural lab settings, our team created portable spin-coating machines using a computer case fan that was modified mechanically to act as the controllable rotating plate. The speed of the fan was controlled through a pulse-width-modulation that used a microcontroller Nano V3 Arduino board and a small LCD module as a display that was programmed to show the rotating speed, the time and the power of the potentiometers that control the duration of the coating. To catch the overflowing ink, the bottom end of the coating machine was covered with aluminum foil, while the top electrode layer was evaporated. 


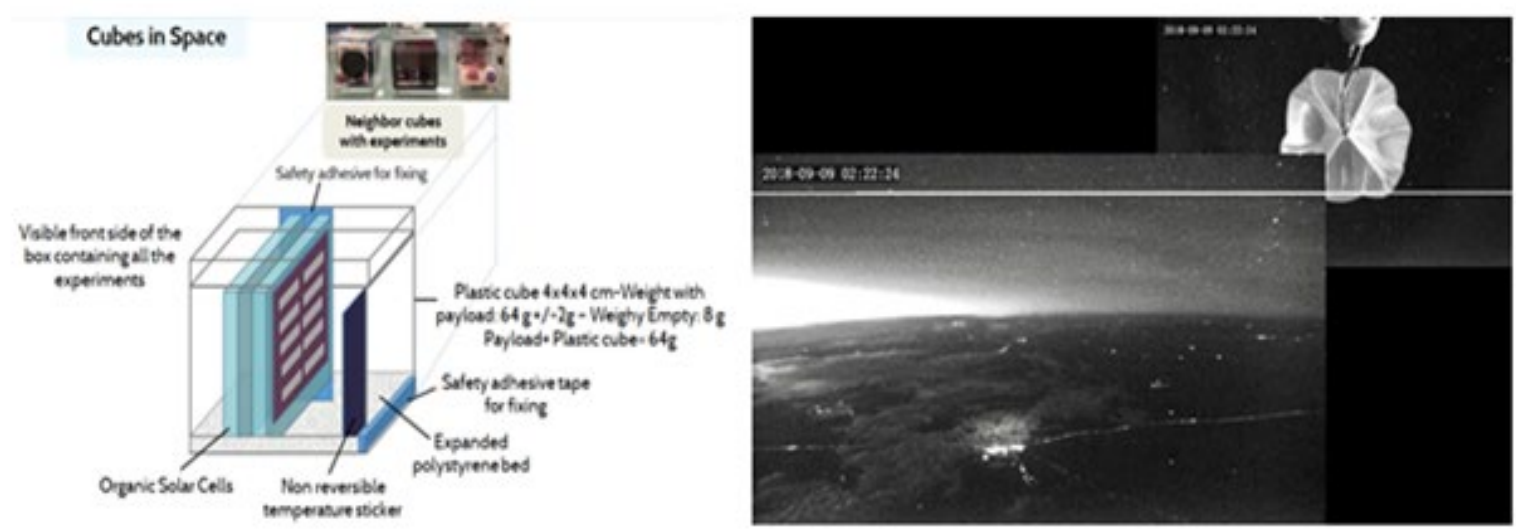

Figure 2. (Left) Cube holder illustration. (Right) The first launch of solar cells attached to an aerostatic balloon that reached an altitude of $37 \mathrm{~km}$, from NASA's Columbia Scientific Balloon Facility in Ft. Sumner, New Mexico through the Cubes in Space Program. Photo Credit: Cubes in Space ${ }^{\mathrm{TM}}$.

Once the OSCs were created, the students are asked to prepare a scientific poster that includes a search for local applications of solar power devices and the proposal of new applications to contextualize the knowledge acquired during the sessions. The poster sessions are designed in such a way that the students not only have a chance to socialize their findings, while at the same time they get to improve their presentation skills, but they were also designed to ensure that the students appropriate all the concepts learned in the lab by generating ideas that can solve problems in their communities and in the world.

\section{LAUNCHING OUR FIRST SOLAR CELLS TO SPACE}

Space exploration and the democratization of outer space is currently facing challenges beyond our human developments in STEM fields, especially in areas related to food and energy production. Solar energy has been one of the main sources of energy used in space exploration (Perlin, 1999; Yang et al., 2020; Koehler, 2019). However, to minimize the area that is occupied by the solar modules, the materials used to generate energy during space exploration have been characterized by their high-power conversion efficiencies and ease of transport at the expense of increased costs associated with their production. The opportunities offered by novel materials including organic molecules like polymers, fullerenes, small molecules, and perovskites- can be an alternative to conventional solar cells in terms of weight, flexibility, and costs (Dennler et al., 2009; Du et al., 2017; Cao et al., 2017; Brabec et al., 2020; Distler et al., 2020; Langner et al., 2020; Dowland et al., 2017). Despite the historically lower efficiencies of these novel materials, recent reports present efficiency values that challenge the use of traditional solar technologies. Therefore, it is necessary to establish the potential use of next-generation solar cells operating under outer space conditions.

Shortly after the organic solar cells were made by our students our team was able to win a spot in the Cubes in Space $^{\mathrm{TM}}$ (CiS) competition, where teams of students from all over the world compete to test their experiments in near space conditions. The experiments that are selected can travel either by being attached to a zero-pressure scientific balloon, or inside an Orion Terrier improved rocket. Each type of space flight implies different environments for the samples allowing the teams to interpret two different sets of data.

As our first proposal was accepted, subsequent proposals for other space missions were presented. This allowed our team to mentor more students and researchers across Colombia, while at the same time exploring new materials in different space conditions. Thus, several different organic solar cells were included in two space missions: one attached to a scientific zero-pressure balloon launched from the NASA Langley Research Center in New Mexico, and another one inside an Orion Terrier Rocket, launched from the NASA Wallops Center in Virginia reaching an altitude of more than $150 \mathrm{~km}$.

This part of the methodology takes the experimental results, and the knowledge gained by the students to a new level. That is, by confronting the students with the possibility of testing their solar cells in different atmospheric chemical conditions, including microgravity and electromagnetic radiation, which are only present in superior layers of the atmosphere, the students were capable of identifying whether these new generation solar materials were apt for space applications. In addition, the students were able to acknowledge the limitations of the materials in order to formulate a scientific hypothesis, and imagine the possible outcomes of the space missions. Figure 2 shows an illustration of the cube holder experiment, and a picture of the first stratosphere experiment. 


\section{LAUNCHING DIFFERENT TYPES OF SOLAR CELLS TO SPACE}

Through the years, our team has guided students from different rural regions of Colombia -some that are not even connected to the power grid and others that have been heavily affected by internal armed conflict- into creating solar cells using a wide variety of materials that have been tested in outer space. For instance, a set of six solar cells made by Colombian students including perovskites cells made by a group of indigenous students from a Wayuú Community in La Guajira, where potable water is scarce and there is no connection to the power grid or connectivity, were launched into the thermosphere inside the Orion Terrier Rocket. After an exhaustive state-ofart review, we learned that the research group of Professor Cardinaletti launched perovskite-solar cell modules into the stratosphere for the first time in 2017, but no other group had ever reported reaching outer space with their experiments on perovskites (Cardinaletti et al., 2018).

On another occasion, rural students from a conflict recovery zone (Oiba, Santander) (Science Clubs International, 2016) used blueberry extract as a photosensitizer to create a set of dyes sensitized solar cells that traveled to the stratosphere aboard a Zero Pressure Balloon. These cells, and other solar organic modules, were meant to measure the voltages and currents produced before, during and after sunlight exposure, as well as, to measure the effects of climatic variations and the rate of degradation. Currently, our team is working in alliance with students from an educational robotics group, named MyRobotTech and directed by David Bustamante. We are currently preparing for international competitions with their mini-arduino robot and their solar car.

\section{MEASURING THE IMPACT OF OUR METHODOLOGY}

Surveys and informational interviews at the end of the program have shown that $81 \%$ of middle and highschool students that have participated in our outreach initiatives have a particular interest in pursuing careers in different STEM fields. Thus far, one of our alumni has had the chance of joining the Space Cubs hosted by NASA with the sponsorship of Coursera CEO Latin America, while two others started a biochemistry engineering collaboration project with ICESI University, which offers a promising future for today's world that depends on advances in technology and biochemical transformation processes to be applied in outer space.

In an effort funded by the Colombian Ministry of Science, we were able provide an international academic experience in Germany to four of our students. In coordination with Dr. Perea, Dr. Cruz, and Professor Brabec, the students were able to explore the Bavarian Centre for Applied Energy Research (ZAE Bayern in German) and the FAU facilities at EnCN in Nuremberg, where they were introduced to inorganic perovskite-based solar cells, and were able to create a set of lab-scale devices. They also attended multiple academic events and met outstanding researchers in the photovoltaic field such as Professor Aldo Boccaccini, Professor Markus Antonietti, as well as a short visit with Professor Gerhard Ertl, Chemistry Nobel Prize Laureate, at the Max Planck facilities in Berlin. This life-changing week allowed our students to experience the life of a scientist and get a wider perspective about careers in STEM.

Finally, to include a gender perspective aimed at propelling scientific exploration for girls from ethnic communities in Colombia, we are searching for private sponsorship to bring a group of girls from underrepresented backgrounds to Boston for a scientific and educational experience. Figure 3 was made to summarize all the projects enrolled in our methodological approaches.

\section{CONCLUSIONS}

Our results show that cutting edge research can reach decentralized sectors of society and produce extraordinary outcomes. By carefully planning and preparing experiments out of the laboratory settings and in alternative learning contexts, we have guaranteed the participation of students from different rural areas that have no previous scientific background.

Our team has counted with the support of several active academics, including professors and graduate students that are interested in the democratization of science as a driver for social change. Our project gained momentum thanks to their contribution, and it allowed the involvement of new actors that escalated the replication and continued execution of our methodology.

Hence, our project stems from a cooperative approach that not only develops STEM education in rural areas, where it is needed the most, but it also contributes to the strengthening of scientific culture in different communities and regions. It is our hope that in the near future, the students that benefited from these types of programs could help increase the sustainable development of their communities. 


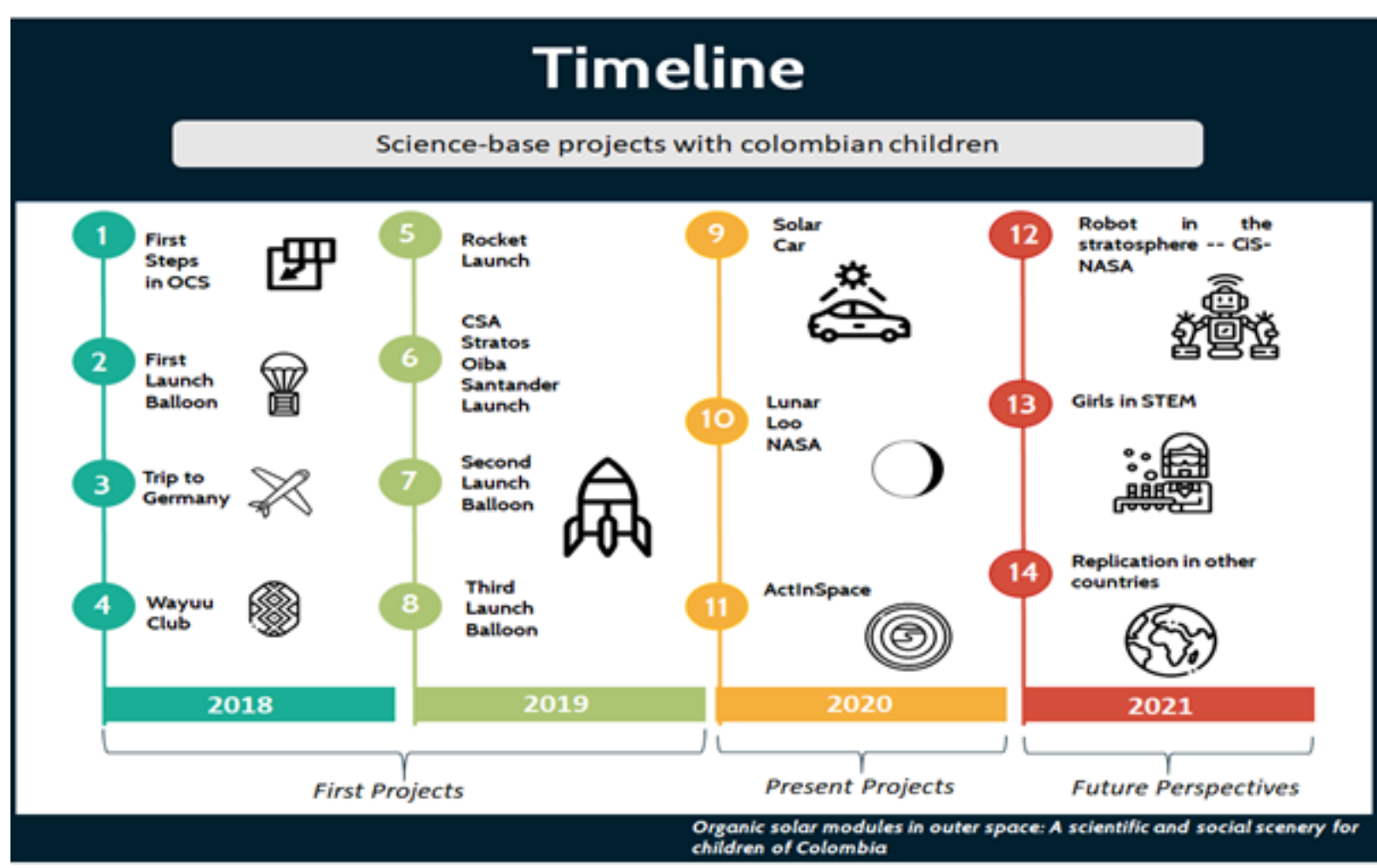

Figure 3. Timeline of the projects that have been implemented by our team in the last three years, and the projects that are in the pipeline for 2021.

\section{REFERENCES}

Ackerman, E. (2020). GITAI Sending Autonomous Robot to Space Station. Available at: https://spectrum.ieee.org/gitai-autonomous-robot-iss.

Brabec, C. J., Distler, A., Du, X., Egelhaaf, H.-J., Hauch, J., Heumueller, T. and Li, N. (2020). Material Strategies to Accelerate OPV Technology Toward a GW Technology. Advanced Energy Materials, 10(43), 2001864. https://doi.org/10.1002/aenm.202001864

Bugga, R. V. and Brandon, E. J. (2020). Energy Storage for the Next Generation of Robotic Space Exploration. The Electrochemical Society Interface, 29(1), 59. https://doi.org/10.1149/2.F08201IF

Cao, T., Chen, N., Liu, G., Wan, Y., Perea, J. D., Xia, Y., Wang, Z., Song, B., Li, N., Li, X., Zhou, Y., Brabec, C. $\mathrm{J}$. and Li, Y. (2017). Towards a full understanding of regioisomer effects of indene-C60 bisadduct acceptors in bulk heterojunction polymer solar cells. Journal of Materials Chemistry A, 5(21), 10206-10219. https://doi.org/10.1039/C7TA01665D

Cardinaletti, I., Vangerven, T., Nagels, S., Cornelissen, R., Schreurs, D., Hruby, J., Vodnik, J., Devisscher, D., Kesters, J., D’Haen, J., Franquet, A., Spampinato, V., Conard, T., Maes, W., Deferme, W. and Manca, J. V. (2018). Organic and perovskite solar cells for space applications. Solar Energy Materials and Solar Cells, 182, 121 127. https://doi.org/10.1016/j.solmat.2018.03.024

Dennler, G., Scharber, M. C. and Brabec, C. J. (2009). Polymer-Fullerene Bulk-Heterojunction Solar Cells. Advanced Materials, 21(13), 1323-1338. https://doi.org/10.1002/adma.200801283

Distler, A., Brabec, C. J. and Egelhaaf, H.-J. (2020). Organic photovoltaic modules with new world record efficiencies. Progress in Photovoltaics: Research and Applications, 29, 24-31. https:// doi.org/10.1002/pip.3336

Dowland, S. A., Salvador, M., Perea J. D., Gasparini, N., Langner, S., Rajoelson, S., Ramanitra, H. H., Lindner, B. D., Osvet A., Brabec, C. J., Hiorns, R. C. and Egelhaaf H.-J. (2017). Suppression of Thermally Induced Fullerene Aggregation in Polyfullerene-Based Multiacceptor Organic Solar Cells. ACS Applied Materials \& Interfaces, 9(12), 10971-10982. https://doi.org/10.1021/acsami.7b00401

Du, X., Jiao, X., Rechberger, S., Perea, J. D., Meyer, M., Kazerouni, N., Spiecker, E., Ade, H., Brabec, C. J., Fink, R. H. and Ameri, T. (2017). Crystallization of Sensitizers Controls Morphology and Performance in Si-/CPCPDTBT-Sensitized P3HT:ICBA Ternary Blends. Macromolecules, 50(6), 2415-2423. https://doi.org/10.1021/acs.macromol.6b02699 
Kang, N.-H. (2019). A review of the effect of integrated STEM or STEAM (science, technology, engineering, arts, and mathematics) education in South Korea. Asia-Pacific Science Education, 5, 6. https:/ / doi.org/10.1186/s41029019-0034-y

Kelley, T. R. and Knowles, J. G. (2016). A conceptual framework for integrated STEM education. International Journal of STEM Education, 3(1), 11. https://doi.org/10.1186/s40594-016-0046-z

Kendall-Taylor, N. (2020). Science of Science Communications: Want to Drive Social Change? Make a stronger case for Science. Georgetown University Center for Social Impact Communication at the School of Continuing Studies. Available at: https://csic.georgetown.edu/magazine/science-science-communications-want-drive-socialchange-make-stronger-case-science/

Koehler, K. (2019). Students Boosting Technical Skills at NASA Wallops' Rocket Week. NASA's Wallops Flight Facility, Wallops Island, Va. Available at: https://www.nasa.gov/feature/wallops/2019/students-boostingtechnical-skills-at-nasa-wallops-rocket-week

Langner S., Häse, F., Perea, J. D., Stubhan T., Hauch, J., Roch L. M., Heumueller, T., Aspuru-Guzik, A. and Brabec C. J. (2020). Beyond Ternary OPV: High-Throughput Experimentation and Self-Driving Laboratories Optimize Multicomponent Systems. Advanced Materials, 32(14), 1907801. https://doi.org/10.1002/ adma.201907801

LeGrand, C. C., van Isschot, L. and Riaño-Alcalá, P. (2017). Land, justice, and memory: challenges for peace in Colombia. Canadian Journal of Latin American and Caribbean Studies / Revue canadienne des études latino-américaines et caraïbes, 42(3), 259-276. https:/ / doi.org/10.1080/08263663.2017.1378381

Nationales MINT (STEM) Forum. (2014). MINT-Bildung im Kontext ganzheitlicher Bildung [STEM-education in the context of holistic education]. Munic: Herbert Utz Verlag.

OECD (2019). PISA 2018 Results (Volume I): What Students Know and Can Do. Paris: PISA, OECD Publishing.

Perea, J. D. (2019). Solubility and Miscibility of Organic Semiconductors for Efficient and Stable Organic Solar Cells Investigated via Machine Learning and Quantum Chemistry Methods [Doctoral dissertation, Friedrich-Alexander-Universität (FAU)].

Perlin, J. (1999). From Space to Earth: The Story of Solar Electricity (pp. 1-11). Ann Arbor, Michigan, USA: Aatec Publications.

Quigley, C. F. and Herro, D. (2016). "Finding the Joy in the Unknown": Implementation of STEAM Teaching Practices in Middle School Science and Math Classrooms. Journal of Science Education and Technology, 25, 410-426. https://doi.org/10.1007/s10956-016-9602-z

Salazar-Lara, L. (2020, December 31). Cultura en CTeI. Available at: https://minciencias.gov.co/cultura-enctei/ondas (Accessed 31 December 2020).

Savage N. (2018). Expanding the reach of science. Nature, 2018, 562 (S11). https://doi.org/10.1038/d41586-01806833-z

Science Clubs International (2016). Available at www.clubesdeciencia.org.

Smith, B. K., Nazario, M. L. and Cunningham, C. C. (2012). Solar Electric Propulsion Vehicle Demonstration to Support Future Space Exploration Missions [Conference Paper]. NTRS - NASA Technical Reports Server.

Yang, J., Bao, Q., Shen, L., Ding, L. (2020). Potential applications for perovskite solar cells in space. Nano Energy, 76, 105019. https://doi.org/10.1016/j.nanoen.2020.105019 